\title{
Prática como Componente Curricular em cursos de licenciatura: um estado do conhecimento
}

\section{The State of Knowledge: Practice as a Curricular Component in the undergraduate courses}

\author{
Emanuelly Wouters Silva (emanuellywouters@gmail.com) \\ Jerônimo Sartori (jetori55@yahoo.com.br)
}

\begin{abstract}
Resumo: Este artigo tem relação com a complexidade que perpassa a formação inicial de professores e o próprio universo da educação escolar. O estudo representa parte dos procedimentos metodológicos traçados para uma investigação no Mestrado Profissional em Educação, com o objetivo de: "investigar teses e dissertações sobre a Prática como Componente Curricular em cursos de licenciatura entre os anos de 2008 e 2018". O Estado do Conhecimento foi elaborado por meio da busca no acervo da Biblioteca Digital Brasileira de Teses e Dissertações - BDTD, no período de 2008-2018, tendo, como descritores: prática como componente curricular, saberes docentes e formação inicial de professores. Os achados mostram a relevância do Estado do Conhecimento e a escassez de pesquisas que tratem da prática como componente curricular articulada com a formação docente.
\end{abstract}

Palavras-chave: Prática como componente curricular; Formação inicial de professores; Saberes docentes.

\begin{abstract}
This article deals with complexity of the teachers inctial traning and the universe of school and education itself. The study presents part of the methodological procedures outlined for an investigation in Post Graduated Program of Professional Education. The aim of the reaserch was: "investigate teses and dissertations related to the Practice as a Curricular Component in the undergraduate courses between the years 2008 and 2018". The investigation, here named as State of Knowledge was elaborated by searching the collection of the Brazilian Digital Library of Theses and Dissertations BDTD, in the period 2008-2018, having as descriptors: practice as a curricular component, teaching knowledge and initial teacher training. The findings show the relevance of the State of Knowledge and the scarcity of research that deals with practice as a curricular component articulated with teacher training.
\end{abstract}

Keywords: Practice as a curricular component; Initial teacher training; Teaching knowledge. 


\section{CONSIDERAÇÕES INICIAIS}

A educação escolar quando intenciona a formação do sujeito para que se aproprie de conhecimentos científicos e valores humanos passa pela formação dos profissionais da educação e, consequentemente, da sua ação pedagógica. Desse modo, ao reivindicar as necessárias mudanças no campo da educação é indispensável olhar para os cursos de licenciatura, que se dedicam à formação docente. $\mathrm{O}$ ato de formar professores não tem a ver somente com o aprofundamento dos conteúdos específicos de uma área, mas também com o aprendizado sobre os fundamentos pedagógicos e didáticos que dizem respeito à docência. Para Pimenta, é imprescindível compreender que: "professorar não é uma atividade burocrática para a qual se adquire conhecimentos e habilidades técnico-mecânicas" (1997, p. 06).

Conforme Moreira (2012), a formação docente no formato 3+1, conhecido pelo fato de que os currículos dos cursos de licenciatura organizavam-se em três anos com disciplinas de conteúdos específicos (bacharelado) e o quarto ano composto por disciplinas com conteúdos de didática. Tal formação pautava-se na ideia de que ensinar consistia em transmitir conhecimento - conteúdo específico -, para, após, aprender como aplicá-lo: "a lógica subjacente é que o bom professor precisa, antes de tudo, deter o conhecimento" (MOREIRA, 2012, p. 03). Cabe-nos realçar que essa lógica de formação deixou resquícios que afetam até hoje os cursos de licenciatura no Brasil (MOREIRA, 2012), ou seja, ainda se ensina os conteúdos específicos isolados da prática pedagógica.

Diante de tais questões, seguimos no enfrentamento da dicotomia que insiste em separar a teoria da prática, tanto nos processos formativos quanto na atuação docente. É, pois, imprescindível, refletir se a prática representa efetivamente a aplicação da teoria, ou se a teoria é mais importante do que a prática e, mais, se a prática basta-se a si mesma sem fundamentação teórica. Nessa perspectiva, pesquisar a formação de professores e seus processos é essencial para que as etapas formativas sejam aperfeiçoadas e os professores sejam cada vez mais qualificados para exercer uma prática educativa democrática, em que a docência esteja alicerçada na relação teoria e prática e na realidade dos educandos.

Entre as derivações acerca da formação de professores, buscamos refletir sobre as contribuições da Prática como Componente Curricular (PCC), implementada com o propósito de fortalecer o processo de formação docente nas licenciaturas. Consideramos que a PCC tem potencial para promover a articulação dos saberes docentes Recebido em: 18/01/2021 
(pedagógicos, da experiência e do conhecimento), quando estruturada e organizada com esse objetivo. Também favorece a articulação entre teoria e prática na formação inicial e permite o contato do licenciando com a Educação Básica, mediante experiências que o aproximam do cotidiano da prática docente futura.

$\mathrm{O}$ ato de formar e formar-se docente torna-se mais significativo quando o licenciando sai das paredes da instituição formadora e vivencia momentos de aproximação com a escola durante a formação inicial, refletindo que a constituição profissional requer a articulação de diferentes saberes, bem como entre teoria e prática. Essa é a perspectiva da Prática como Componente Curricular (PCC) adotada nos cursos de licenciatura, ao prever que o licenciando estude as teorias específica e pedagógica, planeje atividades embasadas em seus estudos e desenvolva-as em diferentes realidades que compõem o espaço profissional.

Esta investigação é parte de uma pesquisa de Mestrado Profissional em Educação e versa sobre a constituição de saberes docentes vinculados a PCC em um curso de licenciatura em Química. Esse curso constitui interesse em estudá-lo pelo fato de ter vivenciado, nele, ricas experiências, que possibilitaram a articulação entre teoria e prática, a articulação de saberes docentes e o contato com a escola em diferentes modalidades e etapas da Educação Básica, enquanto espaço profissional.

O Conselho Nacional de Educação (CNE), por meio da Resolução CNE/CP n ${ }^{\circ}$ 02/2015, estabeleceu uma carga horária obrigatória de 400 horas de PCC, implementadas nos cursos de licenciatura de graduação plena no Brasil. Isso motivounos a desenvolver um Estado do Conhecimento, com o objetivo de compreender a importância da PCC, enquanto articuladora de saberes docentes e viabilizadora do contato do licenciando com seu futuro espaço profissional. A busca por investigações já desenvolvidas favorece a interlocução com outros pesquisadores, que se dedicaram a investigar temáticas similares. Assim, o Estado do Conhecimento para este estudo associa-se ao objetivo geral da pesquisa que consiste em: "compreender de que forma a Prática como Componente Curricular do curso de Licenciatura em Química do Instituto Federal Farroupilha - campus Panambi, contribuiu no processo de formação dos licenciados para a articulação de saberes docentes". A partir desse propósito de pesquisa e da importância de um Estado de Conhecimento para o desenvolvimento de outros estudos, definimos o objetivo deste estudo: "investigar teses e dissertações sobre a 
Prática como Componente Curricular em cursos de licenciatura entre os anos de 2008 e 2018 ".

Diante disso, enlaçados ao propósito de investigação, inicialmente, apresentamos a metodologia do estudo, em seguida, trazemos os achados nas pesquisas selecionadas e, por fim, apresentamos algumas considerações provisórias, pois, o movimento e a dinâmica das sucessivas mudanças agregam permanentemente novos conhecimentos.

\section{TRAJETÓRIA METODOLÓGICA}

Pesquisar é buscar novos horizontes, conhecer espaços que não se imaginava, explorar lugares onde (talvez) ninguém tenha ido, desbravar algo escondido, destapar o que está coberto, descampar uma trilha, nadar por um rio desconhecido, desembaraçar nós feitos, destrinchar matagais, abrir cortinas e janelas, esclarecer o oculto, defrontarse com surpresas, descobrir novos conhecimentos. Desse modo, cabe-nos trazer o destaque de Minayo (2002) de que nenhuma pesquisa é neutra, pois, quando decidimos o que pesquisar, que autores servirão como base teórica e que meios utilizaremos para a pesquisa, estamos nos apoiando em nossas ideologias.

A definição da metodologia de uma pesquisa perpassa três dimensões: técnica, ideológica e científica. A dimensão técnica diz respeito à forma como a pesquisa será realizada, instrumentos, técnicas e sujeitos participantes. A dimensão ideológica é o motivo pelo qual escolhemos o objeto da pesquisa e a forma de pesquisar. Por fim, a dimensão científica une as dimensões técnica e ideológica (MINAYO, 2002).

Gil (2008) destaca a existência de dois grupos de pesquisa: as pesquisas que coletam dados de "papéis" e as que se valem de pessoas, sendo que: "No primeiro grupo, estão a pesquisa bibliográfica e a pesquisa documental. No segundo, estão as pesquisas experimentais, a pesquisa ex-post facto, o levantamento e o estudo de caso" (GIL, 2008, p. 50). Este estudo enquadra-se no primeiro grupo, visto que se apoiou em teses e dissertações para coletar os dados.

O Estado do Conhecimento é a categorização e o registro de produções científicas, agrupando diferentes trabalhos (teses, dissertações, artigos...), mediante as características que os unem conforme tema e área preestabelecidos por quem concretiza uma busca (MOROSINI \& FERNANDES, 2014), com o objetivo de uma "aprendizagem ativa e colaborativa, pela qual o sujeito assume o compromisso com a 
sua reflexão crítica, com a construção de seu objeto e com a inserção no campo científico (MOROSINI, 2015, p. 14). Essa busca permite desenvolver um "descritivo da produção acadêmica e científica sobre o tema que busca investigar, à luz de categorias e facetas que se caracterizam enquanto tais em cada trabalho e no conjunto deles, sob os quais o fenômeno passa a ser analisado" (FERREIRA, 2002, p. 02). O tema deste Estado do Conhecimento refere- se à PCC, enquanto articuladora de saberes docentes na formação inicial de professores.

Tendo o objetivo de "investigar teses e dissertações sobre a Prática como Componente Curricular em cursos de licenciatura entre os anos de 2008 e 2018", acreditamos que o Estado de Conhecimento constituiu-se em metodologia adequada ao desenvolvimento da pesquisa. Assim, ao planejar os métodos, levamos em consideração que: "uma metodologia não se define por uma coleção de técnicas e instrumentos, e sim pela lógica que orienta o processo de investigação" (MAZOTTI, 1991, p. 56), ou seja, sua lógica define-se com base nos pressupostos teóricos existentes sobre os saberes docentes, a formação inicial e a Prática como Componente Curricular.

Morosini (2015) escreve que quando damos início à busca por materiais, geralmente, temos uma ideia de que não há trabalhos relacionados ao tema da pesquisa. Todavia, sempre estamos seguindo um percurso de pesquisa que já teve início outrora, ou seja, estamos dando continuidade e acrescentando discussões ao que já existe sobre o tema no campo científico. Segundo a autora, possuímos crenças e saberes e, "para que ocorra a transformação do fato social em científico, há que se buscar um afastamento deste cotidiano" (2015, p. 06). Após levantar a produção científica que há na área, o pesquisador deve definir as categorias e o modelo de análise a ser utilizado na busca. Também Morosini e Fernandes afirmam que se pode utilizar o que há de "produção reconhecida junto aos órgãos de avaliação da produção nacional. Banco de todas as teses e dissertações produzidas no país com reconhecimento do governo [...]" (2014, p. 03).

Nessa perspectiva, a busca realizou-se na plataforma do acervo da Biblioteca Digital Brasileira de Teses e Dissertações - BDTD, delimitado ao período entre os anos 2008 a 2018, empregando para a busca avançada os descritores: Prática como Componente Curricular, saberes docentes e formação inicial de professores. Após a leitura refinada e a seleção dos trabalhos que possuem vínculo e/ou similaridade com o objeto de estudo em pauta, lemos novamente os resumos, quando estes não 
evidenciaram a clareza que esperávamos, nos debruçamos a ler a introdução e também, entre alguns, as considerações finais. A leitura foi realizada com o olhar atento à articulação ou não da Prática como Componente Curricular com os saberes docentes.

\section{ESTUDOS E SEUS ACHADOS}

No contexto historicamente tradicional em que se desenvolveu a docência, o conhecimento do professor, por muito tempo, constituiu-se desarticulado, com a premissa de que ser docente representava transmitir conceitos e informações, desconsiderando os saberes docentes e enfatizando somente os saberes específicos. Em razão disso, a maior parte dos licenciandos apoia-se no conhecimento científico como suficiente para ensinar bem (PIMENTA, 1997).

Conforme Nóvoa (1992, p. 17), o “desenvolvimento profissional dos professores tem que estar articulado com as escolas e os seus projectos". O campo de atuação do professor é a escola, por isso, o contato com esse espaço proporcionado durante a formação propicia parte de uma experiência profissional que só teria no final da formação, por meio do estágio supervisionado. Além disso, é necessária a interação entre professores e diferentes contextos educacionais e, se realizada durante o curso de licenciatura, representa "um novo sentido às práticas de formação de professores centradas nas escolas" (NÓVOA, 1992, p. 17).

\footnotetext{
É preciso trabalhar no sentido da diversificação dos modelos e das práticas de formação, instituindo novas relações dos professores com o saber pedagógico e científico. A formação passa pela experimentação, pela inovação, pelo ensaio de novos modos de trabalho pedagógico. E por uma reflexão crítica sobre a sua utilização. A formação passa por processos de investigação, directamente articulados com as práticas educativas (NÓVOA, 1992, p. 16).
}

Nessa perspectiva, compreendemos que a formação não pode ser um processo isolado da realidade e da prática educativa. Não se forma um professor dentro de uma instituição, apenas discutindo teorias e conceitos científicos,-sem que haja contato da teoria com o exercício docente. Uma formação que proporcione articulação entre os conhecimentos e, ainda, harmonize-os com a prática, indagando, investigando e refletindo mediante esses aspectos, constituindo um modelo de formação docente inicial que sai do modelo de racionalidade técnica e enfrenta as concepções caracterizadas de tradicionais (SILVA e SCHNETZLER, 2008). 
Edição Especial: I SSAPEC - Simpósio Sul-Americano de Pesquisa em Ensino de Ciências

ISSN: 2595- $4520 \quad$ Vol. 4, n. 3. 2021

Nesse viés, é tarefa das instituições formadoras de professores articular saberes específicos e pedagógicos, pois, ambos e junto com o saber da experiência fazem parte do itinerário de constituir-se docente. Ademais, momentos de articulações entre a teoria estudada e a prática docente também são necessários no processo de formação inicial, considerando-se a possibilidade dessa prática ser desenvolvida no espaço da prática profissional futura na Educação Básica. Neste sentido, a PCC é inserida nos cursos de licenciatura como uma maneira de articulação entre formação acadêmica e o exercício da profissão docente.

Sabendo que os aspectos supracitados estão dentre os objetivos da PCC (Res. CNE/CES no 02/2015), desenvolvemos a busca pelas teses e dissertações publicadas na perspectiva de compreender a importância da PCC nos processos formativos, enquanto articuladora de saberes docentes e viabilizadora do contato do licenciando com o espaço profissional da prática futura. Ademais, o esforço empenhado neste estudo visa potencializar o desenvolvimento da pesquisa de mestrado, bem como aprender com outros pesquisadores que investigam este tema.

A busca pelas teses e dissertações foi desenvolvida na Biblioteca Digital Brasileira de Teses e Dissertações - BDTD, considerando o período de 2008-2018. Utilizamos a busca avançada para inserir os descritores: prática como componente curricular, saberes docentes e formação inicial de professores. Inicialmente, buscamos pelos descritores individualmente e, após, utilizamos mais de um campo para uma busca detalhada. $\mathrm{O}$ quadro relacionado abaixo indica os descritores que utilizamos e quantos trabalhos foram encontrados para cada descritor.

Quadro 1 - Pesquisa de descritores individuais

\begin{tabular}{|c|c|}
\hline TERMO PESQUISADO & TÍTULOS ENCONTRADOS \\
\hline Prática como Componente Curricular & 755 \\
\hline Saberes Docentes & 4.485 \\
\hline Formação Inicial de Professores & 4.543 \\
\hline
\end{tabular}

Fonte: Elaboração dos Pesquisadores. 
Como podemos notar, a plataforma utilizada para a pesquisa oferece uma quantidade ampla de resultados. Entretanto, a pesquisa é sobre os três descritores, por isso, ao realizar a busca utilizando-os concomitantemente - prática como componente curricular + saberes docentes + formação inicial de professores - o resultado reduziu-se em 31 trabalhos.

Segundo Morosini (2015), é preferível realizar a leitura aprofundada de alguns estudos, do que nos sobrecarregarmos de materiais que representam um quantitativo significativo, mas pouco explorados. A plataforma ofereceu-nos um resultado de 31 trabalhos (títulos). Aprofundando a busca, desses 31 títulos que surgiram, apenas quatro aproximaram-se do tema do estudo, assim sendo, realizamos uma nova busca sem o item "formação inicial de professores", com o objetivo de encontrar mais trabalhos e, dessa maneira, localizamos ao todo 102 trabalhos, sendo que, destes, três aproximam-se do tema da pesquisa. Essa redução significativa $(31-4$; 102-3) ocorreu porque a plataforma seleciona os descritores utilizados na busca em todos os campos do documento, dessa forma, aparecem diversos resultados de trabalhos que não tratam do tema Prática como Componente Curricular e Saberes Docentes na formação inicial de professores. Abaixo, segue o quadro 2 com os trabalhos encontrados, os quais constituem o objeto de Estado do Conhecimento.

Quadro 2 - Trabalhos BDTD

\begin{tabular}{|c|c|c|c|c|}
\hline $\mathbf{N}$ & AUTOR & TÍTULO & $\begin{array}{l}\text { LOCAL E } \\
\text { DATA }\end{array}$ & GÊNERO \\
\hline 1 & $\begin{array}{c}\text { FONSECA, } \\
\text { Carlos Ventura }\end{array}$ & $\begin{array}{l}\text { A formação de professores de } \\
\text { Química em Instituições de } \\
\text { Ensino Superior do Rio Grande } \\
\text { do Sul: saberes, práticas e } \\
\text { currículos }\end{array}$ & $\begin{array}{l}\text { Rio Grande } \\
\text { do Sul, } 2014\end{array}$ & Tese \\
\hline 2 & $\begin{array}{l}\text { MARCATTO, } \\
\text { Flávia Sueli } \\
\text { Fabiani }\end{array}$ & $\begin{array}{l}\text { A Prática como Componente } \\
\text { Curricular em projetos } \\
\text { pedagógicos de cursos de } \\
\text { licenciatura em Matemática }\end{array}$ & $\begin{array}{l}\text { São Paulo, } \\
\quad 2012\end{array}$ & Tese \\
\hline 3 & $\begin{array}{l}\text { MONTEIRO, } \\
\text { Francisca Ocilma } \\
\text { Mendes }\end{array}$ & $\begin{array}{l}\text { A Prática como Componente } \\
\text { Curricular na formação de } \\
\text { professores do Curso de } \\
\text { Licenciatura em Biologia no IFPI } \\
\text { campus Floriano }\end{array}$ & $\begin{array}{l}\text { Rio Grande } \\
\text { do Sul, } 2013\end{array}$ & Dissertação \\
\hline 4 & $\begin{array}{l}\text { ORLANDI, Elisa } \\
\text { Margarita }\end{array}$ & $\begin{array}{l}\text { A Prática Pedagógica como } \\
\text { Componente Curricular na } \\
\text { formação de professores: a visão }\end{array}$ & $\begin{array}{c}\text { Santa } \\
\text { Catarina, } \\
2015\end{array}$ & Dissertação \\
\hline
\end{tabular}


de graduandos do curso de

Ciências Biológicas (diurno) da

Universidade Federal de Santa

Catarina

5 RAYMUNDO,

Gislene Miotto

Catolino

\section{Prática de Ensino e Estágio}

Supervisionado: eixos

articuladores na formação inicial

dos professores da Educação

Básica
6 ROCHA, Aurea

Maria Costa

\section{A formação de professores e a} construção de saberes da docência no curso de Pedagogia da UFPE

\section{SILVÉRIO, \\ Lucio Ely \\ Ribeiro}

As Práticas Pedagógicas e os

Saberes da Docência na

formação acadêmico-profissional em Ciências Biológicas

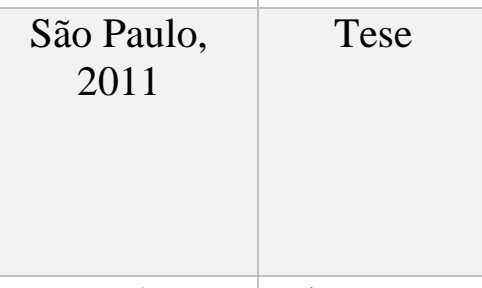

Pernambuco, Dissertação 2008

Santa
Catarina,
2014

Fonte: Elaboração dos pesquisadores.

O primeiro trabalho refere-se a uma tese produzida com base em dados obtidos em diferentes instituições formadoras de professores de Química, tendo como objetivo saber se promovem vinculações entre aspectos teóricos e a prática pedagógica na formação inicial. O pesquisador explorou o contexto das licenciaturas, analisando a produção acadêmica relacionada ao tema. Posteriormente, aprofundou seus estudos em duas licenciaturas específicas, analisando a matriz curricular e desenvolvendo questionários com discentes e docentes do curso. A pesquisa indicou que os cursos analisados privilegiam os saberes específicos do campo da Química, dedicando pouco espaço à teoria e à prática pedagógica, o que dificulta o preparo do professor para o exercício profissional docente.

O segundo trabalho consiste em uma tese que investiga a implementação da PCC nos cursos de licenciatura em Matemática. A pesquisa desenvolvida foi de natureza qualitativa, tendo foco na análise documental. O corpus do estudo foi composto por 30 projetos pedagógicos de cursos de licenciatura em Matemática de diferentes instituições e regiões do país. A pesquisadora buscou analisar de que modo os cursos ofertavam as 400h de PCC obrigatória e de que forma faziam-no. A conclusão a que a pesquisadora chegou foi de que nenhuma das propostas analisadas apresenta articulação entre o conhecimento específico acadêmico e o conhecimento pedagógico escolar, mostrando que persiste uma certa "hierarquia" da teoria sobre a prática. 
No terceiro trabalho é retratado como Estudo de Caso de um curso de licenciatura em Ciências Biológicas, objetivando investigar de que forma são ofertadas as 400h de PCC obrigatórias e se, por meio delas, é promovida alguma articulação entre teoria e prática que contribua para formação e posterior ação docente. A metodologia utilizada consistiu em uma análise documental da proposta curricular do curso, seguida de três entrevistas com docentes, bem como pela realização de um grupo focal com alunos do curso em observação. A pesquisadora concluiu que a Prática como Componente Curricular nesse curso atende e até ultrapassa as 400h de PCC previstas em lei, além de constatar que, dentro dela, realizam-se diversas atividades, que contribuem para a articulação da teoria e com a prática, aproximando a formação inicial das questões da educação básica e qualificando melhor a formação docente no curso.

O quarto trabalho refere-se a uma dissertação que teve como objetivo analisar a Prática como Componente Curricular de um curso de licenciatura em Ciências Biológicas, no que tange a sua contribuição no processo formativo e de construção de saberes dos licenciandos. A pesquisa realizada teve abordagem de natureza qualitativa e o método de coleta de dados ocorreu por meio de um grupo focal composto por alunos em fase de conclusão do curso. Os resultados obtidos indicaram que a Prática como Componente Curricular contribuiu positivamente no processo formativo, os acadêmicos indicaram-na como espaço de auxílio às futuras situações pedagógicas e de construção de saberes essenciais ao exercício da docência.

O quinto trabalho é uma tese que objetivou analisar como as disciplinas de PCC e Estágio de um curso de licenciatura em Pedagogia contribuem para os acadêmicos tornarem-se (re)significadores de saberes. Essas disciplinas são consideradas inovadoras nos métodos, procurando superar a visão tradicional de formação e promover vinculações entre teoria e prática. Nessa perspectiva, desenvolveu-se a pesquisa com abordagem qualitativa, tendo como sujeitos pesquisados quatro docentes do curso e dez acadêmicos que já atuam como docentes. A produção de dados foi obtida por meio da análise documental e das respostas ao questionário que foi aplicado aos investigados. Ao finalizar a pesquisa, ficam as considerações de que a PCC e o Estágio contribuíram significativamente para os licenciandos no que se refere à (ao): reflexão da prática pedagógica; problematização das experiências cotidianas; desenvolvimento de atitude investigativa e conhecimento da realidade, dentre outras mudanças que auxiliam na (re)significação da docência. 
O sexto estudo consiste em uma pesquisa de natureza qualitativa desenvolvida em um curso de licenciatura em Pedagogia, tendo como objetivo conhecer como a PCC contribui para o processo de construção de saberes docentes. A pesquisadora definiu três categorias de análise: formação de professores; prática de ensino e saberes docentes. Os procedimentos utilizados na investigação foram observação participante e análise documental, sendo analisados os documentos de reordenação do curso de Pedagogia e o projeto pedagógico do curso. A observação participante foi desenvolvida nos espaços de formação acadêmica e o exercício profissional, durante as aulas de PCC, a pesquisadora utilizou um diário de campo para anotar os aspectos observados, considerando como sujeitos da pesquisa professores e acadêmicos do curso. Os resultados apontaram que a PCC auxilia na construção de saberes docentes, considerando as várias articulações promovidas durante o curso, entre o espaço formativo e escola de educação básica, este último tido como o espaço de exercício profissional em que o licenciado promoverá situações de aprendizagem junto aos estudantes.

O último trabalho centra-se nos saberes construídos nas práticas pedagógicas de um curso de licenciatura em Ciências Biológicas, objetivando investigar o desenvolvimento de saberes pedagógicos/docentes com base nas disciplinas de PCC e estágio curricular. A abordagem adotada na pesquisa foi qualitativa e os instrumentos utilizados para a produção de dados foram: grupo focal, análise documental (reformas curriculares e o currículo dos cursos de Ciências Biológicas) e entrevista semiestruturada, sendo a análise textual discursiva adotado o procedimento reflexivo para o tratamento da empiria. O grupo focal foi desenvolvido com os acadêmicos do curso de licenciatura em Ciências Biológicas em fase de conclusão, dos quais três foram selecionados para participarem das entrevistas. Com base no tratamento dos dados, o autor sugeriu que a formação no curso necessita aprimorar a associação entre as disciplinas específicas da área da Biologia e as de conteúdos pedagógicos. Também evidencia a necessidade de aperfeiçoar a concepção de prática e de estágio supervisionado adotados nos princípios formativos no curso de licenciatura em Ciências Biológicas. O autor anuncia a imprescindibilidade de alteração no formato da prática como componente curricular, no sentido de que esteja associada à transposição didática e à perspectiva reflexiva sobre o ensino na área biológica. Isso sugere que as ações em 
parceria com escolas e docentes da Educação Básica fortalecem o desenvolvimento de projeto afetos à profissionalidade docente.

\section{AS PESQUISAS SEGUEM... ALGUMAS CONSIDERAÇÕES SEMPRE PROVISÓRIAS}

A elaboração do Estado do Conhecimento representa a materialidade do olhar e da reflexão acerca dos estudos vividos/experienciados, sempre tendo em conta o espaço e o tempo delimitado para cada tema em processo de investigação. Para Morosini \& Fernandes (2014), o ato de dialogar com estudos já realizados potencializa problematizações e movimentos reflexivos, ampliando o horizonte do pesquisador para (re)escrever e produzir sobre o objeto do seu interesse. Neste sentido, o Estado do Conhecimento possibilita identificar, registrar e categorizar aspectos relevantes de estudos efetivados, o que permite vislumbrar o novo e/ou novas formas de abordagem analítica para temáticas similares.

A despeito disso, este processo de investigação acerca dos estudos disponíveis na BDTD contribuiu para conhecer parte do que foi produzido no campo científico relacionado ao tema deste estudo, que busca compreender as contribuições da PCC para a construção de saberes docentes na formação inicial de professores. O que nos chamou atenção foi as características particulares de cada pesquisa, pois, em alguns casos, assemelham-se, já em outros, distanciam-se, obviamente, objetos e olhares diferentes produzem reflexões também diferenciadas.

A análise realizada dá conta de que, em alguns estudos, fica a constatação de que há desarticulação entre teoria e prática no processo de formação docente, considerando, especialmente, a pesquisa realizada nos cursos de licenciatura em Química, Matemática e em um curso de Ciência Biológicas. Esse olhar é produzido quando a dissertação ou a tese é elaborada tendo como objeto de reflexão a matriz curricular do curso, no qual nem sempre existe, de forma clara, a explicitação da PCC, no que tange ao como se dará a articulação entre teoria e prática; em nosso entendimento, esta seria a possibilidade concreta para a efetivação da práxis. Neste sentido, destacamos que entre seus objetivos, a PCC deveria articular teoria e prática, movimento sempre atual a ser discutido e enfrentado no campo da docência. Todavia, temos a concordância de que nem sempre é "possível construir uma teoria sem que ela tenha passado pelo filtro da prática refletida 
em seu locus sócio-cultural, e de uma prática sem reflexão, sem ter um cerne teórico" (FERNANDES e FERNANDES, 2005, p. 03, grifo do autor).

Por sua vez, nas pesquisas em que foram ouvidos alunos e professores, eles destacaram enfaticamente a contribuição da PCC na articulação da teoria com a prática, além de, ao realizar as ações na escola, favoreceu o contato direto com a realidade da Educação Básica. Há o destaque para o fato de que, por intermédio das ações protagonizadas via PCC, viabilizam-se condições para o diálogo, a problematização e a avaliação da prática pedagógica, tanto dos acadêmicos em formação como dos professores que atuam na escola. Outro aspecto relevante procedente dos dados produzidos por meio de questionários e entrevistas diz respeito a que as ações desenvolvidas na escola permitem conhecer a realidade escolar e a dos sujeitos que trabalham e estudam nela.

$\mathrm{O}$ estudo realizado na perspectiva de Estado do Conhecimento permitiu-nos a percepção, em algumas pesquisas, que a PCC como uma das possibilidades de estreitar a relação teoria-prática encontra-se fragilizada em algumas licenciaturas, conforme as considerações dos respectivos pesquisadores. Se considerados os estudos produzidos acerca dessa temática, as fragilidades podem constituir-se em alavancas para aperfeiçoar, tanto o PPC do curso como a atuação dos professores formadores. Embasados em nossos achados, destacamos que a mudança na formação docente não consiste apenas em termos prescritivos a atos normativos, como é o caso do Resolução CNE/CP $n^{\circ}$ 02/2015, que determina a inclusão em todos os cursos de licenciatura de 400h dedicadas à prática pedagógica como componente curricular. A mudança, pois, tem a ver com a postura e o compromisso político e pedagógico por parte das instituições formadoras e dos docentes que atuam nas licenciaturas. A mudança, em nosso entendimento, consiste no acolhimento e no compromisso político e pedagógico daqueles que atuam na formação dos futuros docentes para a educação básica.

As pesquisas que mais se aproximaram do nosso estudo (dois cursos de Pedagogia e dois de Ciências Biológicas) indicam, por meio das metodologias e dos instrumentos utilizados para as ações, que a relação entre saberes docentes e prática como componente curricular mostram-se eficientes em abarcar as experiências dos licenciandos em relação à PCC, enquanto possibilidade articuladora de saberes específicos e pedagógicos. Essas pesquisas apontaram que a PCC auxilia no que se refere à produção de saberes da docência, considerando a pluralidade de ações 
Edição Especial: I SSAPEC - Simpósio Sul-Americano de Pesquisa em Ensino de Ciências ISSN: 2595- $4520 \quad$ Vol. 4, n. 3. 2021

planejadas, executadas e avaliadas pelos licenciandos nos diferentes espaços formativos. Fica explícito, em pelo menos dois dos estudos, que a PCC reverbera em prol da formação dos futuros docentes, oferecendo possibilidades reais para a articulação entre teoria e prática. Nesse processo, vislumbram-se possibilidades para que, a partir dos saberes da experiência, sejam aprimorados os saberes da docência.

Neste sentido, enxergamos a PCC positivamente, haja vista que, como disciplina obrigatória, é também obrigatório que os licenciandos tenham contato com a prática em momentos distintos do curso e não somente no Estágio Curricular Supervisionado. Assim, ambos incluídos no PPC como componente curricular obrigatório mostram-nos um avanço para abarcar parte da prática docente na formação inicial, "trata-se de uma concepção de prática ampliada, constituindo um componente curricular que está presente ao longo do processo formativo" (DA COSTA, DE ALENCAR e BERALDO, 2012, p. 01).

Assim, nosso entendimento é que, durante a prática, o licenciando conhece a realidade e "as situações que os professores são obrigados a enfrentar (e a resolver) apresentam características únicas, exigindo, portanto, respostas únicas: o profissional competente possui capacidades de auto-desenvolvimento reflexivo" (NÓVOA, 1992, p. 16). Desse modo, o aluno-docente, quando em contato com os problemas surgidos no meio escolar, experiencia conjunturas que não ocorrem no cotidiano dentro da instituição formadora, pois, o que se estuda é teorias e hipóteses, mas quando esse contato é propiciado pela instituição, é possível ser investigado e refletido, gerando conhecimentos com base na própria experiência.

Embasados na investigação e na reflexão realizadas, essa etapa do estudo vinculada aos procedimentos metodológicos para a elaboração da dissertação no programa Mestrado Profissional em Educação cumpre com o objetivo de investigar teses e dissertações sobre a Prática como Componente Curricular em cursos de licenciatura entre os anos de 2008 e 2018. Desse modo, os achados auxiliam-nos a reconhecer a relevância do Estado de Conhecimento, visto que tornou possível conhecer o que já existe de produção acadêmica acerca do tema, bem como em que circunstâncias nos cursos de licenciatura está havendo contribuição da PCC na formação de futuros docentes. Cabe-nos, por fim, realçar que o conhecimento que se constrói ao realizar leituras, apontamentos e reflexões a respeito de pesquisas produzidas, que envolvem temas similares, amplia a visão e o interesse pela investigação em pauta. 


\section{REFERÊNCIAS}

BRASIL. Resolução CNE/CP n 02/2015, de 01 de julho de 2015. Define Diretrizes Curriculares Nacionais para a formação inicial em nível superior (cursos de licenciatura, cursos de formação pedagógica para graduados e cursos de segunda licenciatura) e para a formação continuada. Brasília, 2015.

DA COSTA, F. T.; DE ALENCAR, F. L.; BERALDO, T. M. L. A Prática como Componente Curricular: Entendimentos da Comunidade Disciplinar de Educadores Químicos. XVI ENEQ/X EDUQUI-ISSN: 2179-5355, 2012.

FERNANDES, C. M. B.; FERNANDES, S. R. de S. As questões da prática pedagógica como componente curricular nas licenciaturas. UNISINOS. In.: ANPED-GT, v. 4, 2005 .

FERREIRA, N. S. A. As pesquisas denominadas "estado da arte". Educação \& sociedade, v. 23, n. 79, p. 257-272, 2002.

FONSECA, C. V. A formação de professores de química em instituições de ensino superior do Rio Grande do Sul: saberes, práticas e currículos. Repositório UFRGS. 2014.

GIL, A. C. Métodos e técnicas de pesquisa social. 6. ed. São Paulo: Atlas, 2008.

MINAYO, M. C. S.; DESLANDES, S. F. Pesquisa social: teoria, método e criatividade. 25. ed. Petrópolis: Vozes, 2002.

MARCATTO, F. S. F. A prática como componente curricular em projetos pedagógicos de cursos de licenciatura em matemática. Repositório UNESP. 2012.

MAZZOTTI, A. J. A. O planejamento de pesquisas qualitativas em educação. Cadernos de pesquisa, n. 77, p. 53-61, 1991.

MONTEIRO, F. O. M.; FORSTER, M. M. S. A Prática como Componente Curricular na formação de professores do curso de Licenciatura em Biologia do IFPI Campus Floriano: subsídios de inovação. Criar Educação, v. 3, n. 2, 2014.

MOREIRA, Plinio Cavalcanti. $3+1$ e suas (in)variantes: reflexões sobre as possibilidades de uma nova estrutura curricular na licenciatura em matemática. Bolema, São Paulo, v. 26, n. 44, p. 1137-1150, dez. 2012.

MOROSINI, M. C.; FERNANDES, C. M. B. Estado do Conhecimento: conceitos, finalidades e interlocuções. Educação por escrito, 2014.

MOROSINI, M. C. Estado de conhecimento e questões do campo científico. Educação (UFSM), v. 40, n. 1, p. 101-116, 2015. 
Edição Especial: I SSAPEC - Simpósio Sul-Americano de Pesquisa em Ensino de Ciências

NÓVOA, A. Formação de professores e profissão docente. Lisboa: Editora,1992.

ORLANDI, E. A prática pedagógica como componente curricular na formação de professores: a visão de graduandos do curso de Ciências Biológicas (diurno) da Universidade Federal de Santa Catarina. Repositório UFSC. 2015.

PIMENTA, S. G. Formação de professores: saberes da docência e identidade do professor. Nuances, São Paulo, v. 03, 1997.

RAYMUNDO, G. M. C. Prática de ensino e estágio supervisionado: eixos articuladores na formação inicial dos professores da educação básica. Revista Exitus, v. 2, n. 2, p. 19-31, 2012.

ROCHA, Á. M. C. A formação de professores e a construção dos saberes da docência no curso de Pedagogia da UFPE. Repositório UFPE. 2008.

SILVA, R. M. G.; SCHNETZLER, R. P. Concepções e ações de formadores de professores de Química sobre o estágio supervisionado: propostas brasileiras e portuguesas. Química Nova, v. 31, n. 8, p. 2174-2183, 2008.

SILVÉRIO, L. E. R. As práticas pedagógicas e os saberes da docência na formação acadêmico-profissional em Ciências Biológicas. Repositório UFSC. 2014. 